\title{
An ugly nose and a Nazi father: Bad premise for a cardiac rheumatic disorder
}

\author{
Massimiliano Foschi, MD, ${ }^{a}$ Fabrizio Costantino Tancredi, MD, ${ }^{\mathrm{a}}$ and Michele Di Mauro, MD, PhD ${ }^{\mathrm{b}}$
}

\footnotetext{
From the ${ }^{\mathrm{a} H e a r t}$ Disease Department, SS Annunziata Hospital, Chieti, Italy; and ${ }^{\mathrm{b}}$ Cardiovascular Disease Department, University of L'Aquila, L'Aquila, Italy.

Disclosures: Authors have nothing to disclose with regard to commercial support.

Received for publication April 4, 2018; accepted for publication April 6, 2018; available ahead of print May 17 , 2016.

Address for reprints: Michele Di Mauro, MD, PhD, Department of Cardiovascular Disease, University of L'Aquila, Piazzale Tommasi 1, L'Aquila 67100, Italy (E-mail: mdimauro1973@gmail.com).

J Thorac Cardiovasc Surg 2018;156:e101

$0022-5223 / \$ 36.00$

Copyright (c) 2018 by The American Association for Thoracic Surgery

https://doi.org/10.1016/j.jtcvs.2018.04.019
}

The rheumatic disorder reported on by Abe and coworkers ${ }^{1}$ in this issue of the Journal has long been labeled as Wegner granulomatosis, ever since Friedrich Wegener, ${ }^{2}$ a Nazi pathologist working in Poland, ${ }^{3}$ reported 3 cases in 1937, describing the pathologic disorders as vasculitis. Actually, this disease had first been reported by Wegner's friend, a Berlin pathologist named Heinz Klinger, ${ }^{4}$ who in 1932 described a case of destructive sinusitis, lung abscesses, and uremia, characterized by angiitis and granulomas, in a report entitled, "Borderline Forms of Periarteritis Nodosa." Today, this rheumatic disorder is known as granulomatosis with polyangiitis (GPA), and one of the most typical sign is a saddle nose deformity caused by a perforated septum, along with crusting around the nose, stuffiness, and runny and bleeding nose, ${ }^{5}$ - in few words, an ugly nose!

GPA is a form of vasculitis of small and medium vessels associated with anti-neutrophil cytoplasmic antibodies. Although it typically involves the upper and lower airways, lungs, and kidneys, cardiac involvement is estimated in as many as $25 \%$ of cases in the general population and as many as $44 \%$ among patients with severe renal involvement. ${ }^{6}$

The most common cardiac manifestations are pericarditis and coronary arteritis, which are usually medically treated. Although valve involvement is not actually uncommon ( $57.1 \%$ for aortic valve and $14.3 \%$ for mitral valve), as previously reported by Abe and coworkers, ${ }^{1,7}$ there is little evidence of surgical treatment for these cases. The strength of this case series is therefore its use of surgery

\section{References} Pathol. 1937;29:202-10. 455-80.

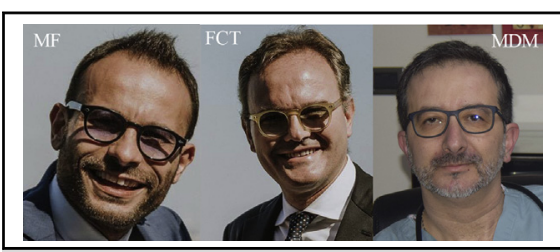

Left to right. Massimiliano Foschi, MD, Fabrizio Costantino Tancredi, MD, and Michele Di Mauro, MD, $\mathrm{PhD}$

\section{Central Message}

The strength of this case series is its use of surgery as a treatment for GPA severely affecting the fibrous heart structure, resulting in multiple valvulopathies, but we need a worldwide registry.

See Article page e93.

as a treatment, with excellent results, in cases in which GPA severely affected the fibrous structure of the heart, resulting in multiple valvulopathies.

Our future challenge in the field of rare heart diseases that can be surgically addressed, such as GPA, could and should be to establish worldwide registries to evaluate the results of surgery on larger cohorts.

1. Abe N, Takahashi H, Inoue T, Tanaka H, Yutaka O. Wegener's granulomatosis of the heart. J Thorac Cardiovasc Surg. 2018;156:e93-7.

2. Wegener F. Uber Generalisierte, septische Gefaesserkrankungen. Verh Dtsch Ges

3. Woywodt A, Matteson EL. Wegener's granulomatosis — probing the untold past of the man behind the eponym. Rheumatology. 2006;45:1303-6.

4. Klinger H. Glenzformer der Periarteritis nodosa. Frankfurt Z Pathol. 1932;42:

5. Kuan EC, Suh JD. Systemic and odontogenic etiologies in chronic rhinosinusitis Otolaryngol Clin North Am. 2017;50:95-111

6. Safak O, Gursul E, Polat M, Akcay F, Tuluce S, Aytemız F, et al. Wegener's granulomatosis with cardiac involvement. Int J Cardiovasc Acad. 2016;2:93-5.

7. Lacoste C, Mansencal N, Ben M'rad M, Goulon-Goeau C, Cohen P, Guillevin L, et al. Valvular involvement in ANCA-associated systemic vasculitis: a case report and literature review. BMC Musuloskelet Disord. 2011;12:50. 